\title{
Pedro Zulen y la filosofía peruana en los inicios del siglo XX
}

\section{Pedro Zulen and Peruvian Philiosophy in the early $20^{\text {th }}$ century}

\author{
PABLO QUINTANILLA
}

Pontificia Universidad Católica del Perú

pquinta@pucp.edu.pe

\section{RESUMEN}

Pedro Zulen (1889-1925) fue un filósofo peruano que recibió la influencia del intuicionismo francés de Bergson, especialmente a través de Alejandro Deustua, y del pragmatismo estadounidense, gracias a una estadia que realizó en la Universidad de Harvard, en la que se familiarizó con la obra de Josiah Royce, Charles Sanders Peirce y William James. Este encuentro de tradiciones, poco usual en su época, le permitió publicar dos libros y muchos artículos académicos $y$ periodisticos de inusual originalidad. Esta contribución se propone presentar la obra filosófica de Zulen mostrando el contexto filosófico peruano en el que surgió. Palabras clave: Zulen, filosofía peruana, pragmatismo, intuicionismo, positivismo.

\section{ABSTRACT}

Perdo Zulen (1889-1925) was a Peruvian philosopher who was influenced by Bergson's French intuitionism, especially through Alejandro Deustua, as well as by American pragmatism, during a stay in Harvard University, where he familiarized himself with the works of Josiah Royce, Charles Sanders Peirce, and William James. This meeting of traditions, rather unusual at the time, enabled him to publish two books and many academic and journalistic articles 
of remarkable originality. This contribution seeks to present Zulen's philosophical work and describe the Peruvian philosophical context in which it emerged.

Keywords: Zulen, Peruvian philosophy, pragmatism, intuitionism, positivism.

Fensamiento filosófico occidental llegó al Perú con el arribo de las primeras órdenes religiosas, hacia mediados del siglo XVI. A partir de entonces, surgieron autores, tanto peruanos como espańoles, afincados en el Perú, interesados en defender el pensamiento escolástico tomista — vigente en aquel momento en España - o en reinterpretarlo creativamente con una mirada diferente. Ese fue el caso de Joseph de Acosta (1539?-1600), Juan de Espinosa Medrano (1629?-1688), apodado «el lunarejo», e Isidoro de Celis (?-1787). ${ }^{1}$

No obstante, estos fueron casos aislados de autores que reflexionaban en suelo peruano, por lo que aún no podía hablarse de una filosofía normalizada en el Perú. El argentino Francisco Romero acunó la expresión «filosofía normalizada ${ }^{2}$ para referir a aquella que no es el producto de una imposición externa forzada, sino una consecuencia natural de procesos sociales e intelectuales que conducen a que una comunidad de personas se plantee preguntas filosóficas, forjando así «el comienzo de una tradición dentro de la que ya cabe hablar con sentido de una línea de desarrollo». ${ }^{3}$ Ciertamente, eso no ocurre de manera abrupta y tiene causas que es necesario reconstruir.

A fines del siglo XVIII, se fundó la Sociedad de Amantes del País que, como es conocido, dio origen a la publicación del Mercurio Peruano. Los intelectuales que participaron en este proyecto recibieron la influencia de los primeros filósofos modernos ilustrados, como René Descartes, Jean-Jacques Rousseau, Voltaire y Baruch Spinoza, pero tampoco puede decirse que hicieran posible un pensamiento filosófico normalizado.

1 Ballón Vargas 2011.

2 Romero 1952.

3 Augusto Salazar Bondy también usa la expresión en su Historia de las Ideas en el Perú contemporáneo. El proceso del pensamiento filosófico. Salazar 1965: 454. 
La primera generación de filósofos peruanos que formó una comunidad de autores que se leían y discutían mutuamente, y que no tenían como único objetivo transmitir el pensamiento europeo en el Perú, sino también procesarlo en función a las necesidades propias de estas sociedades, surgió después de la Guerra del Pacífico. No es inusual que después de un episodio social traumático brote una generación de intelectuales que se proponga repensar lo ocurrido y que, al hacerlo, desarrolle posiciones filosóficas sobre temas menos conectados con las causas sociales que les dieron lugar. Se puede encontrar muchos ejemplos de ello en la historia de la filosofía, siendo un caso paradigmático el origen del pragmatismo estadounidense, que también emergió hacia fines del siglo XIX después de la Guerra de Secesión.

Así, es posible sostener que la primera generación de filósofos peruanos que produjo una filosofía normalizada se dio hacia fines del siglo XIX. Esta incluyó a autores como Manuel González Prada (1848-1918), Alejandro Deustua (1849-1945), Jorge Polar Vargas (1856-1932), Mariano H. Cornejo (1866-1942), Javier Prado Ugarteche (1871-1921) y Manuel Vicente Villarán (1873-1918), entre otros. Lo que en un primer momento unificó a esta generación fue la influencia del positivismo, aunque no tanto del positivismo francés de Auguste Comte (1798-1857) cuanto del positivismo evolucionista del inglés Herbert Spencer (1820-1903). El positivismo había sido muy influyente en Latinoamérica, en gran medida porque representaba todo aquello a lo que las sociedades latinoamericanas aspiraban: orden, modernidad y progreso científico y social. Nuestros países habían salido de largas y destructivas guerras, primero de independencia respecto de España y luego guerras civiles y guerras de fronteras. El positivismo no solo representaba esas promesas de desarrollo, sino también implicaba una ruptura definitiva con el pensamiento conservador y el modelo de sociedad virreinal que se atribuía a España. ${ }^{4}$

Algo curioso es que esta generación se formó en el pensamiento escolástico-tomista, mayormente en la Universidad de San Marcos,

${ }^{4}$ Quintanilla 2006: 69-73. 
aunque en algunos pocos casos también en la Universidad de San Agustín de Arequipa, como fue el caso de Jorge Polar. Posteriormente, sus miembros abrazaron el positivismo precisamente como una reacción a la escolástica y, más adelante, lo abandonaron para adoptar lo que se denominó «espiritualismo», en la línea de Henri Bergson (1859-1941) y Émile Boutroux (1845-1921).

El término «espiritualismo» denominó a una categoría muy amplia de autores que rechazaron las posiciones que consideraron reduccionistas, cientificistas, materialistas y anti-metafísicas de los positivistas, para adoptar un modelo filosófico que consideraba que el espíritu es el elan vitalo la fuerza motivadora que hace posible la libertad y la capacidad creadora del individuo. Por eso el espiritualismo también fue llamado «vitalismo» o «intuicionismo». Los filósofos que recibieron la influencia de Bergson fueron Alejandro Deustua, Javier Prado, Jorge Polar, Mariano Iberico, Ricardo Dulanto, Humberto Borja García y Juan Francisco Elguera. También fue influenciada la llamada generación arielista o generación del Centenario, compuesta por José de Riva-Agüero, Felipe Barreda y Laos, y los hermanos Francisco y Ventura García Calderón. Otros autores influidos por este movimiento fueron el Honorio Delgado tardío, Julio C. Tello, Rubén Vargas Ugarte y Hermilio Valdizán. Los intereses estéticos acercaron a muchos otros al espiritualismo, como Clemente Palma, Alejandrino Maguiña, Ezequiel Burga, Guillermo Salinas Cossío y Juan Bautista de Lavalle, entre otros. ${ }^{5}$

Este es el contexto intelectual en el que se formó el limeño Pedro Zulen (1889-1925), un personaje de gran interés desde varios puntos de vista. Por una parte, procedía de una extracción socioeconómica baja en una época en que la mayor parte de filósofos peruanos solían pertenecer a los sectores acomodados de la sociedad, considerando que la filosofía no era su medio de vida ni su principal actividad. De otro lado, es un representante del mestizaje étnico y cultural en el que fue convirtiéndose progresivamente la sociedad peruana. También refleja un caso de confluencia de tradiciones filosóficas, como veremos pronto. 
Zulen estudió Ciencias Naturales y Matemáticas en la Universidad de San Marcos, decidiéndose posteriormente a estudiar Letras y Derecho. En 1916, viajó a la Universidad de Harvard con el propósito de hacer un postgrado, pero la tuberculosis que ya padecía lo obligó a regresar al Perú, estableciéndose en Jauja con el objetivo de recuperar su salud. En 1920, volvió a viajar a Norteamérica para continuar sus estudios en Harvard, retornando al Perú hacia fines de 1923. Desde entonces y hasta su temprana muerte, ocurrida en 1925, se dedicó a la enseńanza en la Universidad de San Marcos y a trabajar como bibliotecario en la misma universidad.

Nuestro autor publicó dos libros y una gran cantidad de artículos académicos y periodísticos. ${ }^{6}$ Su primer libro procede de su tesis doctoral y lleva como título La filosofía de lo inexpresable: bosquejo de una interpretación y una critica de la filosofia de Bergson. ${ }^{7}$ El segundo, Del neohegelianismo al neorrealismo. Estudio de las corrientes filosóficas en Inglaterra y los Estados Unidos desde la introducción de Hegel hasta la actual reacción neorrealista, apareció en 1924, solo un año antes de su fallecimiento. ${ }^{8}$

Fueron dos las influencias principales en la formación filosófica que Zulen recibió en el Perú. Por una parte, el positivismo de Comte y Spencer y, de otro lado, el intuicionismo de Bergson. En el caso del positivismo de Comte, frente al que reacciona Bergson, uno de sus rasgos más notables es el rechazo a la metafísica, es decir, a la posibilidad de acceder a alguna forma de conocimiento sobre objetos no materiales y que no recurra a la evidencia empírica. Eso se asociaba al cientificismo, esto es, al reconocimiento de la prioridad de la ciencia por encima de cualquier otra forma de conocimiento. Estas dos tesis conducían a una concepción de la historia humana conformada por tres estadios, siendo el primero la Antigüedad religiosa, el segundo el Medioevo metafísico y el tercero la Modernidad científica. Estos tres estadios coincidían, de acuerdo con Comte, con tres momentos en el desarrollo humano:

${ }^{6}$ Quiroz, Quintanilla y Rojas 2015. Casi toda la obra de Zulen está reeditada en Pedro Zulen: Escritos reunidos. Todas las citas en el artículo refieren a esta edición.

7 Zulen 1920.

8 Zulen 1924. 
la niñez, la adolescencia y la adultez. ${ }^{9}$ Spencer adoptó las líneas principales de Comte, pero le ańadió el evolucionismo de Darwin, que también influyó en los filósofos peruanos de fines del siglo XIX.

Sin embargo, como vimos, la generación de filósofos peruanos que formó a Zulen se desencantó del positivismo y volvió su mirada al espiritualismo. Las razones que condujeron a este tránsito son varias, pero pueden resumirse en la decepción producida por suponer que, ante las dificultades de intentar conocer aquello que excede a las posibilidades de las ciencias empíricas, deberíamos abandonar todo juicio acerca de ello. ${ }^{10}$ A esto se sumó la tensión producida por las inclinaciones estéticas de la mayor parte de estos filósofos peruanos, muchos de los cuales también eran poetas, y la fe católica de varios de ellos, lo que entraba en conflicto con las tesis centrales del positivismo. Jorge Polar es probablemente el autor que representa con mayor claridad esa tensión. ${ }^{11}$ Pero es imposible que uno abandone una posición filosófica a la que alguna vez adhirió sin que algunos rasgos de esta se conserven de alguna manera. Eso ocurrió con los espiritualistas peruanos.

Así, la formación que Zulen tuvo en el Perú estuvo en manos de filósofos espiritualistas con un complejo pasado. Sin embargo, o quizá por ello, el primer libro de Zulen es un cuestionamiento radical de los presupuestos del espiritualismo. Aunque aprecia a Bergson, Zulen reconstruye sus influencias en William James, James Ward, Arthur Schopenhauer y Félix Ravaisson. ${ }^{12}$ Zulen sostiene que siendo Bergson original, lo es precisamente por haber reordenado sus diversas influencias. Respecto a ese punto, ataja lo siguiente:

$[S]$ u esfuerzo, aunque hermoso, solo muestra, una vez más, que el destino de la Filosofía parece ser ese cambiar sucesivamente de posición los problemas o modificar la nomenclatura, y si hay progreso es el del claro planteamiento de las cuestiones. ${ }^{13}$

9 Comte 2002a y 2002b.

${ }^{10}$ Quintanilla, 2009.

${ }^{11}$ Polar 1925. Quintanilla 2004: 70-71.

12 Zulen, 1920: 34-35.

${ }^{13}$ Ib.: 33. 
Algo semejante se puede decir sobre el propio Zulen. Pero lo más interesante de su libro es su tesis central, según la cual en Bergson conviven con dificultad el intuicionista místico con el lógico racional, siendo un error cuestionar a uno de ellos con los instrumentos conceptuales del otro.

Bergson pretende oponer al rígido esquematismo conceptual, el flujo íntimo de la realidad; al poder analítico y mutilador de la razón, la fuerza intuitiva del espíritu. ${ }^{14}$

Es necesario decir que una semejante convivencia ocurre también en el propio Zulen. Pero la diferencia entre ambos autores se nota en el estilo. Mientras Bergson se deja llevar con frecuencia por la retórica, lo que dificulta reconocer las tesis que propone y los argumentos con que las defiende — por lo que sería justo decir que desarrolla un cierto estilo impresionista - Zulen adopta un estilo filosófico de gran claridad argumental, aunque no exento de buena prosa literaria. Ese estilo se marcará aun más después de su paso por Harvard.

Influido por Immanuel Kant, Bergson considera que la realidad en sí misma no puede ser conocida y, en tanto heredero de Descartes, piensa que solo podemos conocer la realidad que se nos presenta en la intuición, siendo esta un flujo temporal.

El argumento de Bergson es decirnos que la realidad, objeto de la filosofía, es inexpresable, y lo que nosotros alcancemos será solo sensible, pero de ninguna manera expresable, porque nuestro lenguaje que ha sido creado por nuestra inteligencia en relación con el mundo de la materia inerte, es inadecuado para expresar la vida. ${ }^{15}$

Zulen presenta dos objeciones a esta posición. En primer lugar, considera que no es posible conocer el flujo interno de la conciencia prescindiendo de los objetos con los que ella está relacionada. En esto ya evidencia la influencia del pragmatismo estadounidense — al cual dedicará su segundo libro- y en particular de Charles Sanders Peirce y James,

${ }^{14}$ Ib.: 37.

${ }^{15}$ Ib.: 42. Cursivas del autor. 
para quienes no solo el yo se constituye en relación con los otros yoes y con los objetos del mundo sino, en un importante sentido, el yo los incluye.

¿Sabemos qué es el Yo en sus más hondas profundidades? ¿Qué es mi conciencia? (...) $[\mathrm{N}]$ o existe más que por relación a otros yo y otras realidades. ${ }^{16}$

Pero, de otro lado, considera Zulen que si uno parte de las premisas de Bergson, está condenando a su filosofía a «un ilusionismo psicológico, a un espejismo de la duración real, que en cuanto quiere constituir un sistema filosófico, no avanza más que el agrietado racionalismo». ${ }^{17}$

Así pues, aunque Zulen considera que el espiritualismo acierta al reaccionar ante el positivismo y sus diversas formas de reduccionismo, piensa también que la propuesta de Bergson fracasa. Al tomar distancia de Bergson, Zulen se aleja también de la filosofía en la que fue formado en San Marcos, lo que lo condujo a volver sus ojos a la filosofía que se estaba cultivando en Inglaterra y Estados Unidos. Así fue que en 1924 publicó su segundo libro.

Es curioso que el libro estuviera dedicado a su maestro, quizá el espiritualista peruano paradigmático, Mariano Iberico. Aunque Zulen ya había tomado distancia de esta posición filosófica y en este texto lo reafirma, su aprecio por Iberico es independiente de las diferencias intelectuales. El libro está abocado a analizar el desarrollo de la filosofía anglosajona a fines del siglo XIX y comienzos del XX. En esos años, los filósofos ingleses y estadounidenses se encontraban trabajando, mayoritariamente, en diversas formas de neohegelianismo, como una reacción al positivismo de Spencer. Es digno de notar, por tanto, que el interés de Zulen, tanto al escribir sobre Bergson como sobre los neohegelianos angloamericanos, se haya dirigido a comprender las distintas reacciones que generó el positivismo. Pero los neohegelianos, por su parte, dieron lugar a dos tipos de reacciones. De un lado, la naciente filosofía analítica, representada en Inglaterra por Bertrand Russell, George Edward Moore y el primer Ludwig Wittgenstein. De otro lado las formas tempranas

\footnotetext{
${ }^{16} \mathrm{Ib} .: 48$.

${ }^{17} \mathrm{Ib} .: 55$.
} 
de pragmatismo, representadas por Peirce, Josiah Royce, William James y John Dewey.

En este segundo libro, Zulen tiene un estilo más maduro y preciso; también es más puntual en sus cuestionamientos a los autores y, como en su primer libro, evidencia una amplia cultura filosófica, lo que le permite debatir con los autores y no solo hacer exégesis de ellos. El texto tiene dos líneas de argumentación. Por una parte le interesa explicar cómo surgen las reacciones al neohegelianismo, a las que de manera genérica denomina «neorrealistas». La segunda línea argumentativa es más propositiva y se propone defender las posiciones de Royce y Peirce, a quienes considera neohegelianos, aunque de una variedad diferente, pues contienen ya las tesis pragmatistas sobre la inseparabilidad entre la teoría y la acción. Zulen se propone mostrar que el neorrealismo es insuficiente porque no da cuenta del mundo espiritual; aquí podemos observar la presencia del espiritualismo no plenamente abandonado.

[E]l neorrealismo aparece menos realista que el idealismo, por cuanto rechaza una parte de la realidad, la irreductible, eterna realidad espiritual. (...) La crítica del realismo en general, hecha por Royce, que ya hemos expuesto, es válida también para este realismo. ${ }^{18}$

En el libro pasa revista al neohegelianismo inglés — Francis Bradley y Bernard Bosanquet—, el neohegelianismo en Estados Unidos — la Escuela de San Luis, y aquí ubica también a Peirce y Royce-, el pragmatismo de James, el instrumentalismo de Dewey, nuevamente el intuicionismo de Bergson, y culmina con un apéndice dedicado a la obra y el compromiso político de Bertrand Russell, respecto de lo que se sintió particularmente identificado.

Zulen moriría tempranamente en 1925, como consecuencia de la tuberculosis, un año después de haber publicado este libro. Su influencia en la vida intelectual peruana fue múltiple. Por una parte introdujo muy tempranamente, aunque cuestionándolos, la filosofía analítica y el pragmatismo. De otro lado, mostró a sus contemporáneos que es posible leer 
a los filósofos clásicos y de renombre internacional sin pretender ser solo exégetas o epígonos de ellos sino también analizándolos críticamente, que es lo Zulen hacía con los autores a quienes más admiraba.

Algo de tanta importancia como su actividad académica es la participación activa de Zulen en la problemática social de su tiempo. Fue miembro fundador de la Asociación Pro-Indígena y escribió innumerables artículos académicos y periodísticos sobre temas permanentes y de coyuntura, los cuales van desde interpretaciones de Kant, Spencer y James, pasando por la situación de los indígenas peruanos, hasta tópicos como la literatura de su tiempo, el futuro de la China, la irrigación de la costa peruana y la doctrina Monroe. Zulen nunca se reconoció marxista; es más, se declaró «libertario», ${ }^{19}$ pero siempre tuvo una posición decidida en defensa de los sectores sociales marginados. En muchos puntos, sobre todo en lo concerniente al problema del indio y de la tierra, coincidió en posiciones con Mariátegui, a quien, sin embargo, también cuestionó. Quizá la mejor manera de categorizarlo es como un socialista democrático.

De sus artículos periodísticos, hay dos temas que me gustaría destacar. Por una parte, sus lúcidas y siempre ácidas reflexiones críticas sobre el estado de la educación en el Perú. De otro lado, el artículo titulado «¿Cómo celebraremos nuestro centenario?», dedicado al intelectual arequipeño Francisco Mostajo, uno de los fundadores, en 1901, del Partido Liberal Independiente. Ciento dieciséis años después de haber sido escrito aquel artículo, el Perú es decididamente otro país, aunque muchas de las taras que Zulen detecta aún se mantienen. En lo relativo a la filosofía, no volvió a aparecer una generación tan cohesionada como la que surgió a fines del siglo XIX, lo que tiene tanto un lado negativo tanto como uno positivo. Lo primero, porque sigue siendo difícil que se constituya una tradición de intelectuales que, atentos a lo que ocurre en el mundo, dialoguen y se alimenten mutuamente. Lo segundo, porque hoy se observa mucha más diversidad de posiciones y temas de interés de lo que ocurría en los tiempos de Zulen.

${ }^{19}$ Quiroz, Quintanilla y Rojas: 433-435. En un sentido diferente al que se suele usar hoy, pues Zulen consideraba que «el hombre ha nacido libre y sin embargo vive esclavizado", refiriéndose principalmente a los indígenas peruanos. 
Algunos de los rasgos más importantes que deberíamos recordar de este autor son su autonomía intelectual, su diferenciación personal frente a las presiones intelectuales y políticas de su época, y la coherencia que evidenció entre su trabajo filosófico y su participación en la sociedad civil.

\section{BIBLIOGRAFÍA}

Ballón Vargas, José Carlos (ed.). 2011. La complicada historia del pensamiento filosófico peruano. Siglos XVII y XVIII. Lima: Fondo Editorial de la Universidad Mayor de San Marcos.

Comte, Auguste. 2002a. Curso de filosofía positiva. Barcelona: Folio. . 2002b. Discurso sobre el espiritu positivo. Barcelona: Folio.

Escajadillo, César; Quintanilla, Pablo y Richard Orozco (ed.). 2009. Pensamiento y acción. La filosofía peruana a comienzos del siglo XX. Lima: Instituto Riva-Agüero y Pontificia Universidad Católica del Perú.

Mejía Valera, Manuel. 1963. Fuentes para la historia de la filosofía en el Perú. Lima: Imprenta de la Universidad San Marcos.

Polar, Jorge. 1925. Confesión de un catedrático. Arequipa: Tipografía Cuadros.

Quintanilla, Pablo. 2004a. «Del espejo al caleidoscopio. Orígenes y desarrollo de la filosofía en el Perú». Areté. Vol. 16, núm. 1: 43-79.

. 2004b. «Jorge Polar y el desencanto del positivismo». En Rivara de Tuesta, María Luisa (ed.). La intelectualidad peruana del siglo XX ante la condición humana. Tomo 1. Lima: Editorial Gráfica Euroamericana.

. 2006. «La recepción del positivismo en Latinoamérica». Logos latinoamericano. Vol. 1, núm. 6: 65-76.

Quiroz, Rubén; Quintanilla, Pablo y Joel Rojas (ed.). 2015. Pedro Zulen: Escritos reunidos. Lima: Fondo Editorial del Congreso del Perú.

Romero, Francisco. 1952. Sobre la filosofía en América. Buenos Aires: Raigal.

Salazar Bondy, Augusto. 1965. Historia de las ideas en el Perú contemporáneo. El proceso del pensamiento filosófico. Lima: Moncloa, S.A. 2 t.

Zulen, Pedro. 1920. La filosofía de lo inexpresable: bosquejo de una interpretación y una critica a la filosofia de Bergson. Lima: Talleres Tipográficos Sanmarti y Cía. 1924. Del neohegelianismo al neorrealismo. Estudio de las corrientes filosóficas en Inglaterra y los Estados Unidos desde la introducción de Hegel hasta la actual reacción neorrealista. Lima: Editorial Lux.

Fecha de recepción: 8/VIII/2018

Fecha de aceptación: 10/IX/2018 